\title{
Evaluation of Sawdust and Rice Husks as Fillers for Phenolic Resin Based Wood-Polymer Composites
}

\author{
Marieme Josephine Lette ${ }^{1 *}$, Elhadji Babacar Ly², Diene Ndiaye ${ }^{2}$, Akito Takasaki ${ }^{1}$, \\ Toshihiro Okabe ${ }^{3}$
}

${ }^{1}$ Graduate School of Engineering and Science, Shibaura Institute of Technology, 3-7-5 Toyosu, Koto-ku, Tokyo, Japan

${ }^{2}$ UFR des Sciences Appliquées et de Technologie, Université Gaston Berger de Saint-Louis, Saint-Louis, Sénégal

${ }^{3}$ Molecular Engineering Institute, Kinki University, 11-6 Kayanomori, Iizuka, Fukuoka, Japan

Email: *md16084@shibaura-it.ac.jp

How to cite this paper: Lette, M.J., Ly, E.B., Ndiaye, D., Takasaki, A. and Okabe, T. (2018) Evaluation of Sawdust and Rice Husks as Fillers for Phenolic Resin Based Wood-Polymer Composites. Open Journal of Composite Materials, 8, 124-137. https://doi.org/10.4236/ojcm.2018.83010

Received: June 12, 2018

Accepted: July 24, 2018

Published: July 27, 2018

Copyright (c) 2018 by authors and Scientific Research Publishing Inc. This work is licensed under the Creative Commons Attribution International License (CC BY 4.0).

http://creativecommons.org/licenses/by/4.0/

\section{(c) (i) Open Access}

\begin{abstract}
We produced Wood-Polymer Composites (WPCs) with phenolic resin (PR) filled with saw dust (SD) and rice husks (RH) in a PR:fillerratio of 60:40 wt.\%. $\mathrm{RH}$ and SD were grinded and sieved into particles $<160 \mu \mathrm{m}$. The aim of this research work was to evaluate sawdust and rice husks as fillers for sustainable phenolic resin based WPCs. Therefore, we investigated the thermal stability of $\mathrm{PR} / \mathrm{RH}$ and PR/SD WPCs then we studied and compared the tensile, flexural properties of $\mathrm{PR} / \mathrm{SD}$ and $\mathrm{PR} / \mathrm{RH}$ WPCs samples, as well as their dimensional stability after water absorption test. Furthermore, through ultraviolet light exposure, we evaluated the effects of photo-oxidation on the water stability and mechanical properties of PR/RH and PR/SD WPCs samples compared to unexposed ones. PR filled with SD presented better mechanical properties compared to PR/RH WPCs samples. However, PR/RH WPCs showed good mechanical properties, and better thermal resistance and better water repulsion capabilities compared to PR/SD WPCs samples. Although, long time UV exposure ended up lowering considerably the mechanical properties and water resistance of $\mathrm{PR} / \mathrm{SD}$ and PR/RH WPCs, both RH and SD offer great added value as fillers for PR based WPCs; SD having better interactions with PR matrix compared to RH.
\end{abstract}

\section{Keywords}

Wood-Polymer Composite, Phenolic Resin, Sawdust, Rice Husks, Mechanical Properties, Thermal Stability, Ultraviolet Effects, Water Absorption Properties

\section{Introduction}

The world's global population is steadily increasing. Along with it, waste genera- 
tion, decreasing of natural resources and global warming effects are major concerns for the next generation. Throughout the world, tremendous research works are being conducted in order to bring sustainable solutions to those issues [1] [2]. As far as we are concerned, wood-polymer composites, with their desirable properties such as, low cost, low carbon foot-print, renewable and environmental friendly, offer great added value to industries such as automotive, construction, marine, electronics and various consumer goods [2] [3]. Basically, wood-polymer composites are made out of wood waste and polymeric matrix, thermoplastic or thermosetting polymer [4].

Phenolic resins are synthetic polymers obtained from reaction between phenol and formaldehyde [5]. Their synthesis started in early 1900s with the Belgian-American chemist Leo Henricus Arthur Baekeland [6]. Due to their desirable properties such as high thermal resistance, high creep and fatigue resistance, good dimensional stability, electrical insulation and poor heat conduction, phenolic resins have long been used in coatings, adhesives and composites as well [7].

Rice is one of the most cultivated crops across the world. In fact, around 600 million tons of rice paddies are produced globally each year [8]. According to [9], rice is the primary source of food for billions of people in the world and for every ton of rice produced; about 0.23 tons of rice husks are formed. Rice husks present desirable properties such as low bulk density, toughness, abrasiveness, biological attacks resistance; they have thus a wide range of application: reinforcement/filler for building materials, insulation, panel boards manufacturing [8] [9].

Furniture and wood processing factories are producing huge amount of sawdust waste. Sawdust is mainly used to make wood pellets as firewood, and offer good value added when used for particle board, or used as reinforcement in composite materials [10].

In regard to these waste generation and the disposal issues, it appeared relevant to us to combine the desirable properties of phenolic resin, rice husks and sawdust. Therefore, in this research work, we manufactured wood-polymer composites made with phenolic resin (PR) filled with sawdust (SD) and rice husks (RH) and evaluated their sustainability. Samples were manufactured through hot-press method then subjected to thermal, tensile, flexural, and water absorption tests. Furthermore, as WPCs are mainly used for outdoor application such as fencing, railing, flooring [11], they are more likely to be affected by photo-degradation. Thus, we exposed samples to ultraviolet light of $365 \mathrm{~nm}$ of wavelength, at $60 \mathrm{H}$ for different durations and studied their tensile, flexural and water absorption properties compared to that of unexposed samples. Through scanning electron microscopy, we analyzed the surface morphology of samples, the fractured surface morphology as well as the fiber/matrix interface before and after UV exposure.

\section{Materials and Methods}

\subsection{Material Preparation and Manufacturing Process}

Cedar wood sawdust SD obtained from Aomori Japan, and rice husks RH from a 
rice processing factory in Saint-Louis, Senegal, were grinded into particles between $160 \mu \mathrm{m}$ and $250 \mu \mathrm{m}$ in size, with a WARING Commercial Laboratory Blender. SD and $\mathrm{RH}$ were then oven dried at $150^{\circ} \mathrm{C}$ for $30 \mathrm{~min}$ to remove moisture content. Phenolic resin with a molecular density of $134.134 \mathrm{~g} / \mathrm{mol}$ was used. We prepared then formulations of $60 \mathrm{wt} . \%$ of Phenolic resin and $40 \mathrm{wt} . \%$ of SD and $\mathrm{RH}$ respectively; matrix and filler were mixed together in a ITO SEISAKUSHO PSL-1M ball mill machine for 10 hours. In Table 1, we reported the characteristics of SD, RH [9] [12] and PR.

With an AS ONE hot-press machine, samples were manufactured through Hot-press method at $180^{\circ} \mathrm{C}$ for $20 \mathrm{~min}$, applying $20 \mathrm{MPa}$ of pressure after 10 min of heating. We manufactured PR/RH and PR/SD WPCs samples (PRH and PSD) for tensile test, water absorption test and three-point bending test. For each test, five samples were tested. The samples dimensions were as below:

Tensile test: Length: $119 \mathrm{~mm}$, Grip section Width: $14 \mathrm{~mm}$, Cross-section area: $18 \mathrm{~mm}^{2}$, Gage length: $29 \mathrm{~mm}$ );

Flexural test: (Length: $94 \mathrm{~mm}$, Width: $25 \mathrm{~mm}$, Thickness: $4 \mathrm{~mm}$ );

Water absorption test: (Diameter: $10 \mathrm{~mm}$, Height: $10 \mathrm{~mm}$ ).

\subsection{Test Procedures}

Some samples were exposed to ultraviolet light using an AS ONE Handy UV lamp SLUV-6:

UV intensity light source to $50 \mathrm{~mm}$ :

Long-Wavelength (365 $\mathrm{nm}): 1274 \mu \mathrm{W} / \mathrm{cm}^{2}$

Short-Wavelength (254 nm): $1112 \mu \mathrm{W} / \mathrm{cm}^{2}$

For our experiment, sample were exposed to UV light at $60 \mathrm{H}$ of frequency and $365 \mathrm{~nm}$ wavelength, range of UVA which represent $95 \%$ of UV light that reach the Earth surface. The distance from samples to light source was set at 13.5 $\mathrm{cm}$ and Table 2 shows different durations of samples exposure.

Tests performed on UV exposed and unexposed samples are described below.

Thermo-gravimetric analysis (TGA) was performed on PR, RH and SD to study their thermal degradation process. For this analysis, we used a BRUKER AXS-TG-DTA2020SA. Using $10 \mathrm{mg}$ as samples' weight under air atmosphere, we set the target temperature at $1000^{\circ} \mathrm{C}$ starting from $25^{\circ} \mathrm{C}$ at a heating rate of $20^{\circ} \mathrm{C} / \mathrm{min}$ up to $600^{\circ} \mathrm{C}$ then $10^{\circ} \mathrm{C}$ to $1000^{\circ} \mathrm{C}$; the reference sample was $10 \mathrm{mg}$ of

Table 1. Characteristics of RH, SD and PR.

\begin{tabular}{ccccc}
\hline Filler & Cellulose $\%$ & Hemi-cellulose $\%$ & Lignin $\%$ & Others $\%$ \\
\hline Cedar SD & 45 & 13.2 & 29.3 & $\begin{array}{c}\text { Extractive: } 10.2 \\
\text { Ash: } 0.2\end{array}$ \\
RH & $25-35$ & $18-21$ & $26-31$ & $\begin{array}{c}\text { Silica }\left(\mathrm{SiO}_{2}\right): 15-17 \\
\text { Others: } 2-5\end{array}$ \\
Matrix & $\begin{array}{c}\text { Density } \\
\text { g/mol }\end{array}$ & Molecular Formula & $\begin{array}{c}\text { Glass Temp. } \\
{ }^{\circ} \mathrm{C}\end{array}$ & Max Curing Temp. ${ }^{\circ} \mathrm{C}$ \\
PR & 134.134 & $\mathrm{C}_{8} \mathrm{H}_{6} \mathrm{O}_{2}$ & 53 & $\sim 160$
\end{tabular}


Table 2. Samples' UV exposure time and dose.

\begin{tabular}{cccc}
\hline Samples & $\begin{array}{c}\text { Exposure } \\
\text { time (days) }\end{array}$ & $\begin{array}{c}\text { Total } \\
\text { UV dose }(\mathrm{J})\end{array}$ & $\begin{array}{c}\text { Total UV } \\
\text { dose } / \text { area }\left(\mathrm{J} / \mathrm{cm}^{2}\right)\end{array}$ \\
\hline PSD & 0 & 0 & 0 \\
PRH & 7 & 19262.88 & 105.695 \\
PSD_1 & & & 181.191 \\
PRH_1 & 12 & 33022.08 & \\
PSD_2 & & & \\
PRH_2 & & & \\
\hline
\end{tabular}

Alumina ( $\alpha$-Al2O3) powder. Mass loss as a function of heating temperature was plotted to analyze the thermal degradation process of samples.

The tensile test was performed at room temperature, with an SHIMADZU Tension and Compression Testing Machine (AG-50KNX). The testing speed was set at $0.5 \mathrm{~mm} / \mathrm{min}$. Tensile strength $\left(\sigma_{T}\right)$ and Young's modulus $\left(E_{T}\right)$ were calculated using the following equations.

$$
\begin{gathered}
\sigma_{T}=\frac{F_{\max }}{A} \\
E_{T}=\frac{\sigma}{\varepsilon}
\end{gathered}
$$

$F_{\max }:$ max load supported

$A$ : Cross-sectional area

$\sigma$ and $\varepsilon$ : Stress and Strain at any point of tangent of linear part of stress-strain curve portion between $5 \%$ and $15 \%$ of maximum strain, where no crack has not yet occurred.

Three-point bending test were performed at room temperature with a Techno Graph NMB TG-50 kN, and TU3D-10kN as load cell model. The Crosshead speed was set at $0.5 \mathrm{~mm} / \mathrm{min}$ and the length of the support span was $\mathrm{L}=60 \mathrm{~mm}$. The flexural strength $\left(\sigma_{f}\right)$, and the flexural modulus $\mathrm{E}_{\mathrm{f}}$ were calculated using the following equations.

$$
\begin{gathered}
\sigma_{f}=\frac{3 F L}{2 w t^{2}} \\
E_{f}=\frac{L^{3} m}{4 w t^{3}}
\end{gathered}
$$

$$
\begin{aligned}
& \boldsymbol{F}=\text { Load at fracture } \\
& L=\text { support span length } \\
& W=\text { width } \\
& \boldsymbol{t}=\text { thickness } \\
& \boldsymbol{m}=\text { gradient/Slope of the initial straight line portion of load/deflection curve. } \\
& \qquad E_{f}=\frac{L^{3} m}{4 w t^{3}} \quad E_{f}=\frac{L^{3} m}{4 w t^{3}} \text { Water absorption test }
\end{aligned}
$$

The water absorption was performed by soaking samples in room temperature 
water. To investigate water absorption properties of $\mathrm{PR} / \mathrm{SD}$ and $\mathrm{PR} / \mathrm{RH}$ WPCs samples, we measured the \%water uptake of samples after 4 hours, 8 hours and 24 hours. Prior to soaking into water, samples were oven dried at 120 for $30 \mathrm{~min}$ then weighed. After $4 \mathrm{~h}, 8 \mathrm{~h}, 24 \mathrm{~h}$ and $72 \mathrm{~h}$, samples were weighed again. The percentage of water uptake was calculated using the following equation.

$$
\% \text { water uptake }=\frac{w_{t}-w_{i}}{w_{i}} \times 100
$$

$W_{i}$ : initial weight; $w_{i}$ : weight after a time $t$ in water.

Scanning Electron Microscopy (SEM)

The fractured surface morphology and fiber/matrix interactions were observed and analyzed through scanning electron microscope. The SEM analysis was performed with a SHIMADZU Field Emission SEM JEOL JSM-7610F at 20 KV.

\section{Results and Discussion}

\subsection{Thermal Stability}

The TGA analysis was performed on the PR/SD, PR/RH composites and on PR, to evaluate their thermal degradation process. As shown in Figure 1, PR showed high thermal stability up to $350^{\circ} \mathrm{C}$. From that point, the degradation drastically accelerated up to $600^{\circ} \mathrm{C}$ with nearly $40 \%$ mass loss. This phase corresponds to the degradation of volatiles and polymeric system [7]. From $600^{\circ} \mathrm{C}$, residual PR continued degrading which indicate the disintegration of the polymeric structure and the decomposition of PR into char, representing $60 \%$ of PR initial weight. The same degradation process was observed for PR/SD and PR/RH, however, due to the presence of organic fillers, the drastic degradation started earlier. In fact, around $220^{\circ} \mathrm{C}, \mathrm{PR} / \mathrm{SD}$ and $\mathrm{PR} / \mathrm{RH}$ showed dramatic mass loss of $47 \%$ up to $600^{\circ} \mathrm{C}$. This phase mainly corresponds to the degradation of the components of SD and RH. In fact, as lignocellulosic materials, SD and RH are

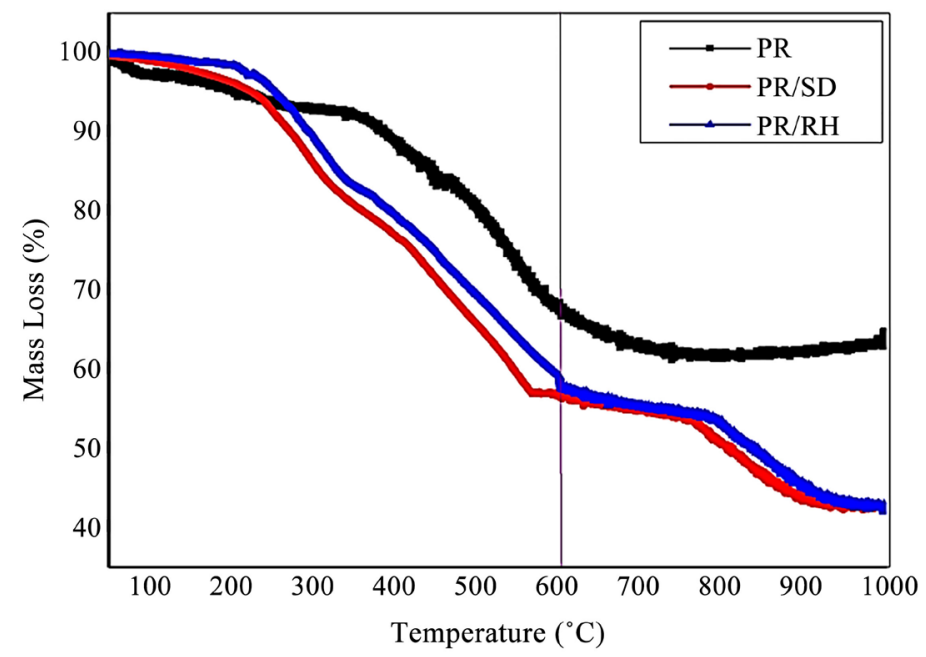

Figure 1. TGA curves of PR/SD, PR/RH and PR. 
composed of hemi-cellulose which thermally degrade faster, from $220^{\circ} \mathrm{C}$ up to $315^{\circ} \mathrm{C}$, cellulose degrading from $315^{\circ} \mathrm{C}$ to $400^{\circ} \mathrm{C}$, and lignin which degrade earlier, at $140^{\circ} \mathrm{C}$, but slower than hemi-cellulose and cellulose. It can be present beyond $400^{\circ} \mathrm{C}$ [13]. After $600^{\circ} \mathrm{C}, \mathrm{SD}$ and $\mathrm{RH}$ completely decomposed into ash leaving PR residuals to continued composing into char representing $~ 40 \%$ of composites initial weight.

However, we can clearly see in Figure 1 that PR/RH presented better thermal stability compared to $\mathrm{PR} / \mathrm{SD}$. In fact, for the same temperature, $\mathrm{PR} / \mathrm{RH}$ composite presented an average of $2.4 \%$ less mass loss than $\mathrm{PR} / \mathrm{SD}$. This can be attributed to the fact that RH has considerable content in silica (Table 1) which is a mineral component having much higher thermal resistance than any other components of the fibers [14]. Table 3 summarizes the thermal properties of PR, PR/SD, PR/RH WPCs.

\subsection{Mechanical Properties}

\subsubsection{Tensile Test}

We evaluated the tensile properties of PR/SD and PR/RH WPCs. Figure 2 shows the values of (a) tensile strength and (b) young's modulus and the \%tensile strain at break of the composite before and after UV exposure. Before exposure to UV radiation, PR/SD WPCs showed tensile strength of $34.497 \mathrm{MPa}$ and young's modulus of $23.272 \mathrm{MPa}$, while PR/RH WPCs showed $34.089 \mathrm{MPa}$ of tensile strength and $20.910 \mathrm{MPa}$ in young's modulus. The tensile properties of PR/SD and PR/RH were slightly similar; but PR/SD showed higher tensile strength and modulus compared to PR/RH WPCs. In fact, SD provided better elasticity and load bearing capabilities as filler compared to RH. However, considering the brittle nature of $\mathrm{PR}$, these values are still low when compared to thermoplastic based WPCs, which possess relatively high tensile properties [9] [15].

$\mathrm{UV}$ are strong radiation that can initiate bond breaking, especially $\mathrm{C}-\mathrm{H}$ bonds which are weaker, thus leading to creation of unstable functional groups then polymer inter-chain linkage that lead to increasing polymer molecular weight and further to polymer degradation for long UV exposure time [16]. This latter is mainly responsible of materials loss in strength after long time UV exposure. However, after seven days of UV exposure, we notice an increase in strength of $6.392 \%$ of PR/SD WPCs and a decrease in strength of nearly $19 \%$ of PR/RH WPCs. The behavior of PR/RH WPCs due to its higher content in lignin, rather than cellulose or hemicellulose, was somehow predictable. In fact, lignin is most

Table 3. Summary of Thermal properties of PR, PR/RH, PR/BF and PR/SD WPCs.

\begin{tabular}{ccccc}
\hline Samples & $\begin{array}{c}\text { Thermal Stability } \\
\text { region }\end{array}$ & $\begin{array}{c}\text { Decomposition } \\
\text { temperature }\left({ }^{\circ} \mathrm{C}\right)\end{array}$ & $\begin{array}{c}\text { mass loss } \\
25^{\circ} \mathrm{C} \text { to } 600{ }^{\circ} \mathrm{C}\end{array}$ & $\begin{array}{c}\text { Residuals } \\
1000^{\circ} \mathrm{C}\end{array}$ \\
\hline PR & Up to $350^{\circ} \mathrm{C}$ & 600 & $32.26 \%$ & $63.22 \% \mathrm{Char}$ \\
$\mathrm{PR} / \mathrm{RH}$ WPC & $\mathrm{Up}$ to $220^{\circ} \mathrm{C}$ & 580 & $40.918 \%$ & $42.49 \%$ Char \\
$\mathrm{PR} / \mathrm{SD}$ WPC & $\mathrm{Up}$ to $220^{\circ} \mathrm{C}$ & 556 & $42.93 \%$ & $36.01 \% \mathrm{Char}$ \\
\hline
\end{tabular}




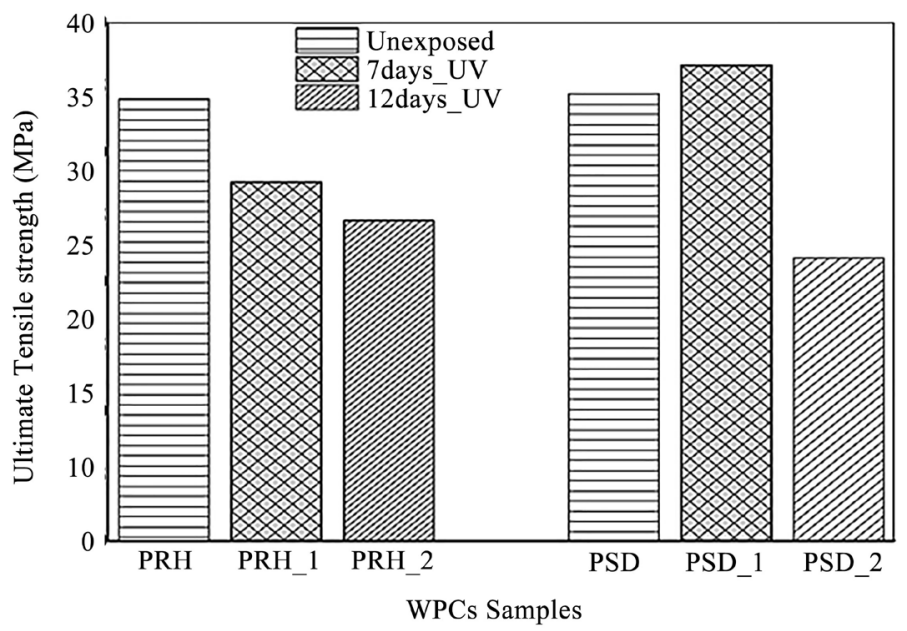

(a)

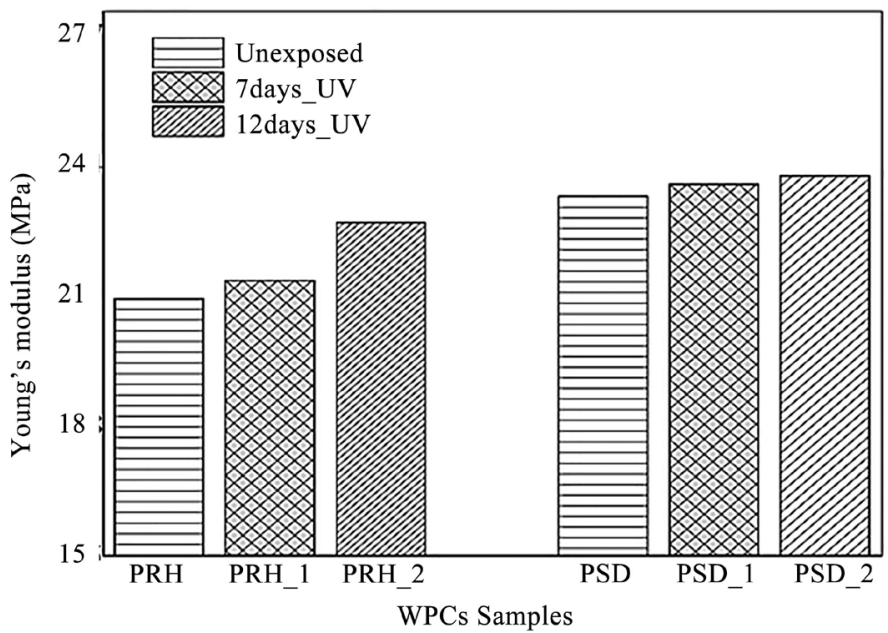

(b)

Figure 2. (a) Tensile strength and (b) Young's modulus of PR/SD and $\mathrm{PR} / \mathrm{RH}$ WPCs before and after 7 and 12 days of UV exposure.

sensitive to photo-oxidation compared to cellulose and hemi-cellulose [11]. Thus, the photo-oxidation reaction initiated by UV radiation embrittled PR's polymer chains as well as RH's lignin and caused further degradation leading to lower tensile properties over exposure time. Actually the same process occurred in PR/SD WPCs; however, we can assume that in this case, due to the higher cellulose content in SD, the inter-chain linkage promoted more fiber/matrix interactions at their interface and less damage to the polymeric chains thus allowing the composite material to gain in strength [17]; but still, the lignin degradation increased the surface wettability of the fibers by leaving cellulose rich surfaces [11]. However, after 12 days of exposure, we noticed loss in strength for booth composites PR/SD and PR/RH WPCs, PR/SD more than PR/RH. Regarding the composites young's modulus, they both showed increase in modulus as we increased the exposure, PR/RH WPCs more than PR/SD WPCs; in fact, due to the advanced degradation of composite's components occurring during UV exposure, the samples developed better resistance to deformation and became 
stiffer. From these results, we can clearly state that PR/RH has better weathering properties than $\mathrm{PR} / \mathrm{SD}$ even though $\mathrm{PR} / \mathrm{SD}$ showed higher strength. In fact, over long time exposure to UV, PR/SD showed a loss in tensile strength of 36.77\% and gained $2.02 \%$ in stiffness while PR/RH WPCs lost $27.48 \%$ in tensile strength and gained $8.36 \%$ in stiffness.

\subsubsection{Flexural Test}

In Figure 3 we evaluated the Flexural strength (a) and Flexural modulus of $\mathrm{PR} / \mathrm{SD}$ and PR/RH WPCs. We can clearly see that PR/SD WPCs showed better flexural properties than PR/RH WPCs. In fact, PR/SD WPCs showed flexural strength of $61.824 \mathrm{MPa}$ and flexural modulus of $2.595 \mathrm{GPa}$ while PR/RH WPCs had $46.472 \mathrm{MPa}$ of flexural strength and $2.016 \mathrm{GPa}$ of flexural modulus. The stress transfer and load bearing performances were indeed better for PR filled with SD rather than PR filled with RH.

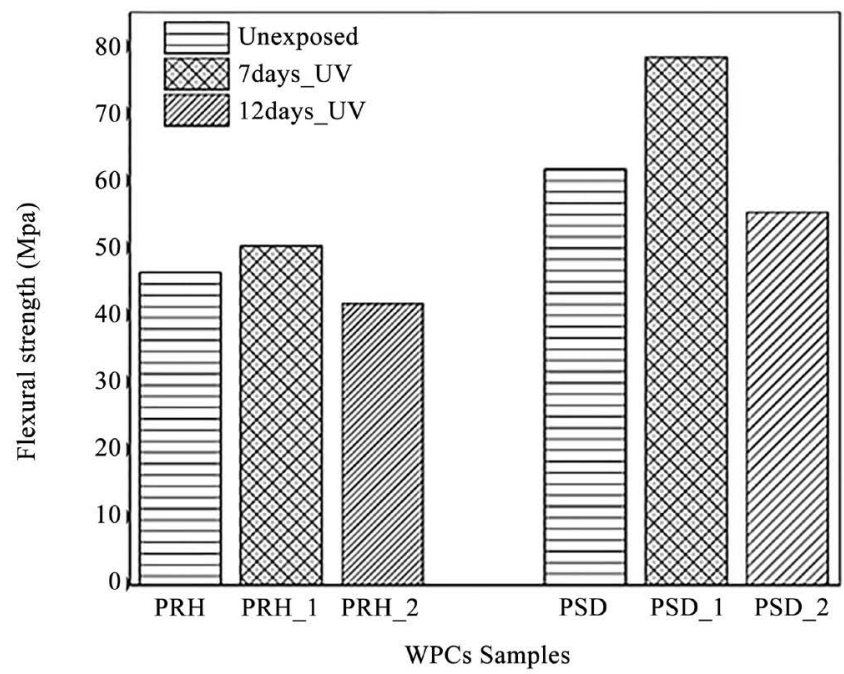

(a)

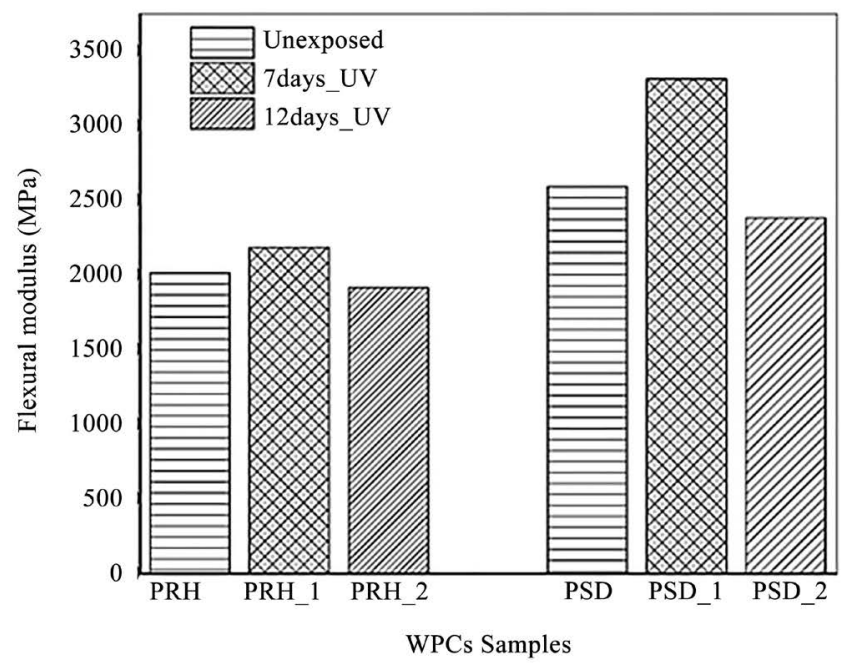

(b)

Figure 3. (a) Flexural Strength and (b) Flexural Modulus of PR/RH and PR/SD WPCs before and after 7 and 12 days of UV exposure. 
After seven days of UV exposure, we noticed an increase in flexural strength in both composites, $\mathrm{PR} / \mathrm{SD}$ more than $\mathrm{PR} / \mathrm{RH}$. UV radiation initiated bond breaking and inter-chain linkage that increased the fiber/matrix interface and the composites stiffness just enough to confer them higher flexural strength. Nevertheless, for the reasons stated earlier for the tensile test results, the increase in flexural strength was lower for PR/RH (+8.5\%) than PR/SD (+26.96\%). However, when we exposed the composites for longer time, further reactions occurred and led to polymers degradation and stiffening that explain the loss in elasticity thus loss in flexural strength and modulus. In fact, after 12 days of UV exposure, PR/SDWPCs showed a flexural strength of $55.395 \mathrm{MPa}$ and a modulus of $2.382 \mathrm{GPa}$ while PR/RH had $41.825 \mathrm{MPa}$ of flexural strength and $1.915 \mathrm{GPa}$ of flexural modulus; these values being lower than that of unexposed PR/SD and PR/RH WPCs. Again, with regards to these results, PR/RH WPCs have better weathering properties than PR/SD. After long UV exposure, PR/RH WPCs lost 9.99\% in flexural strength and 5\% in modulus; while PR/SD WPCs lost $10.4 \%$ in flexural strength and $8.19 \%$ in modulus.

\subsection{Water Absorption Test}

Figure 4 describes the water absorption tendency of PR/RH and PR/D WPCs. We investigate the rate of absorption of composites over increasing soaking time into water. $\mathrm{PR} / \mathrm{RH}$ showed better water repulsion properties compared to $\mathrm{PR} / \mathrm{SD}$. In fact, after $24 \mathrm{H}$, PR filled with $\mathrm{RH}$ absorbed water up to $0.1398 \%$ while PR/SD absorbed $0.069 \%$ more than PR/SD. However, over increasing soaking time, samples water absorption capabilities lowered down. For instance, after $4 \mathrm{H}$ in water, $\mathrm{PR} / \mathrm{RH}$ absorbed $0.0993 \%$; after $8 \mathrm{H}$ the composite absorbed $0.0269 \%$ more and kept absorbing but in smaller amount. Indeed, after $24 \mathrm{H}, \mathrm{PR} / \mathrm{RH}$ absorbed just $0.0136 \%$ more than at $8 \mathrm{H}$; this pattern kept going after $72 \mathrm{H}$ and will keep going until the composites reached their saturation in water; which was close to $0.1434 \%$ water uptake for PR/RH and near $0.2165 \%$ for PR/SD.

In Figure 5 we reported the \% water uptake of PR/RH and PR/SD before and after UV. Natural fillers are highly hydrophilic due to their content in hemicellulose; which is mainly responsible of moisture absorption and biological degradation [17]. As stated earlier after analysis of mechanical properties of composites, lignin is more sensitive to UV compared to other filler's components. Thus, its degradation by photo-induction leaves the fillers more cellulosic thus more hydrophilic [11]. In fact, after 7 days of UV exposure, the water absorption tendency of composites dramatically increases; PR/RH absorbed $0.4640 \%$ of water, which is 3.32 times higher than the \% water uptake of the unexposed PR/RH sample. PR/SD WPCs also absorbed 3.06 times more water than unexposed samples. Furthermore, after 12 days of UV exposure composite samples absorbed even more; we measured \% water uptake of $0.5324 \%$ for $\mathrm{PR} / \mathrm{RH}$ and $0.7342 \%$ for PR/SD. Still, we observed that with effects of photo-oxidation, $\mathrm{PR} / \mathrm{RH}$ showed fewer tendencies to absorb water compared to PR/SD WPCs. 


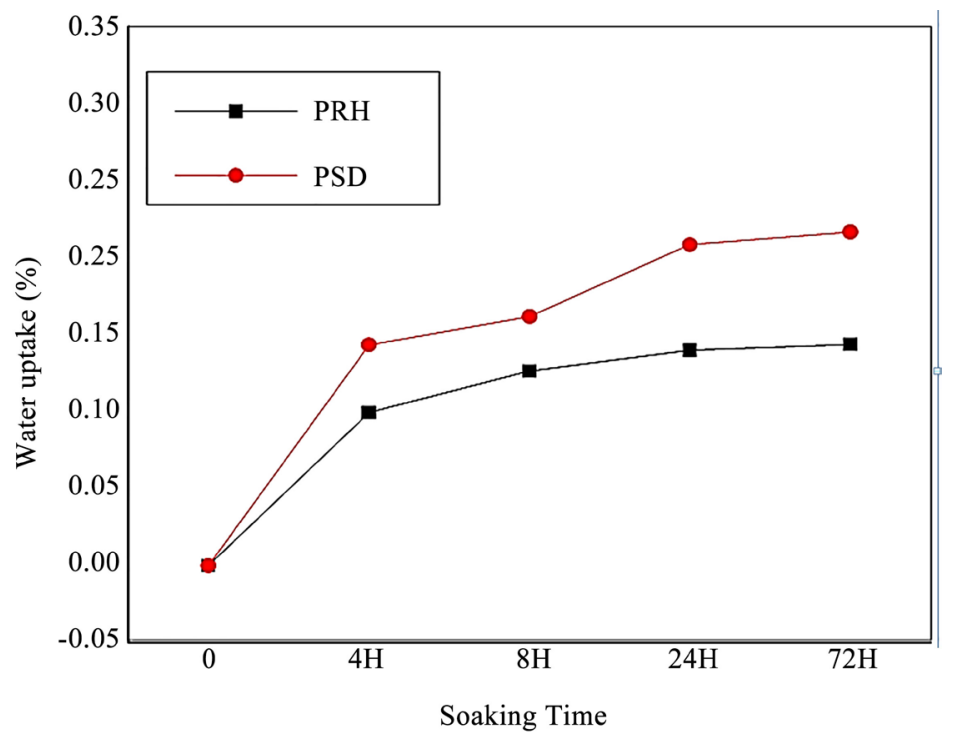

Figure 4. \% water uptake of PR/SD and PR/RH WPCs after 4, 8, 24 and 72 hours of soaking in water.

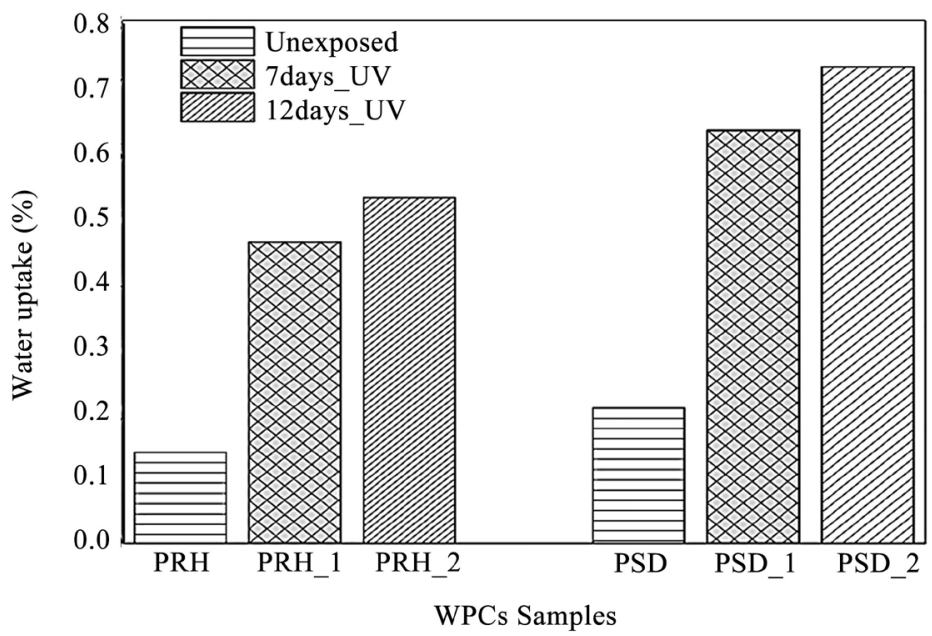

Figure 5. \% water uptake of UV exposed and unexposed PR/RH and PR/SD WPCs after $24 \mathrm{H}$ of soaking time.

\subsection{SEM Analysis}

The SEM analysis was performed to analyze fractured surface morphology of composites and the interface between fillers and phenolic resin. Fiber and matrix interactions are mainly through mechanical interlocking, hydrogen or covalent bonding and through wetting process [18]. This latter was our main interest when conducting SEM analysis. In Figure 6 we can observe the fiber/matrix adhesion in PR/SD (a) and PR/RH (b). SD fibers had good adhesion in phenolic resin, $\mathrm{RH}$ as well but less than $\mathrm{SD}$, probably due to the presence of mineral silica layers in RH which confer less compatibility between RH and PR. From these images, we can understand why PR/SD showed better mechanical properties than PR/RH WPCs. 


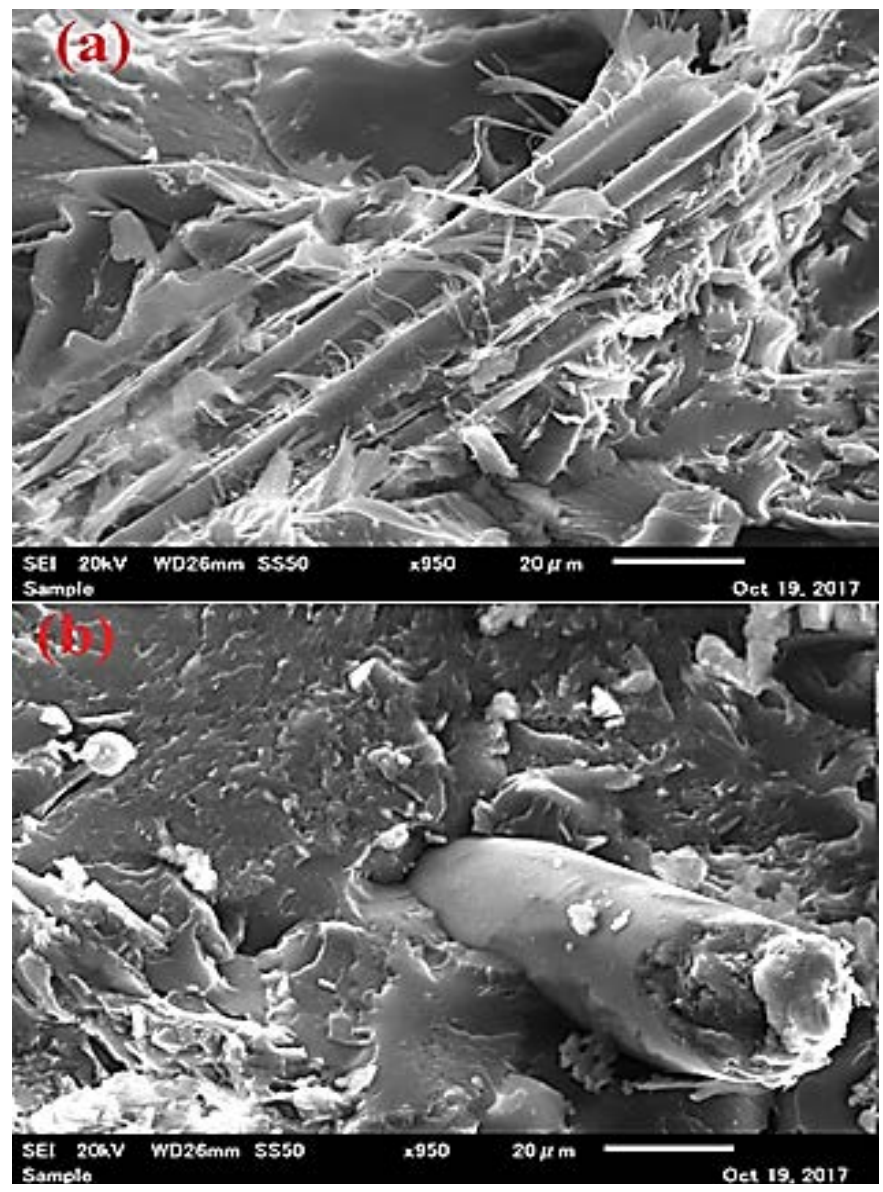

Figure 6. Fractured Surface morphology and fiber/matrix adhesion in (a) PR/SD and (b) PR/RH WPCs.

As well, after analysis of the fiber/matrix interface and composites fractured surface morphology after UV exposure, we could better understand and sustain the results of tensile and flexural test. In Figure 7, we can observe after 7 days of UV, SD and PR had better interactions at their interface (a), the wetting between fiber and matrix was better than in unexposed samples which prove the gain in strength of PR/SD after 7 days of UV exposure. For PR/RH WPCs (b) on the other side, the fiber matrix wetting was also better than unexposed samples. However, the depletions on the composite's fracture surface suggested an important increase in brittleness for both $\mathrm{PR} / \mathrm{RH}$ more than PR/SD WPCs samples.

Figure 8 shows the fiber/matrix adhesion and surface morphology of (a) $\mathrm{PR} / \mathrm{SD}$ and (b) PR/RH after 12 days of UV exposure. Both composites presented poor fiber/matrix wetting, rough and depleted surfaces; mainly due to the brittle failure mode and degradation of the polymeric system and fillers micro-chemical structure. $\mathrm{PR} / \mathrm{RH}$ however showed greater damage compared to PR/SD WPCs.

These observations helped us have an overview of the mechanism through which UV affects the mechanical performances of PR/RH and PR/SD WPCs. 


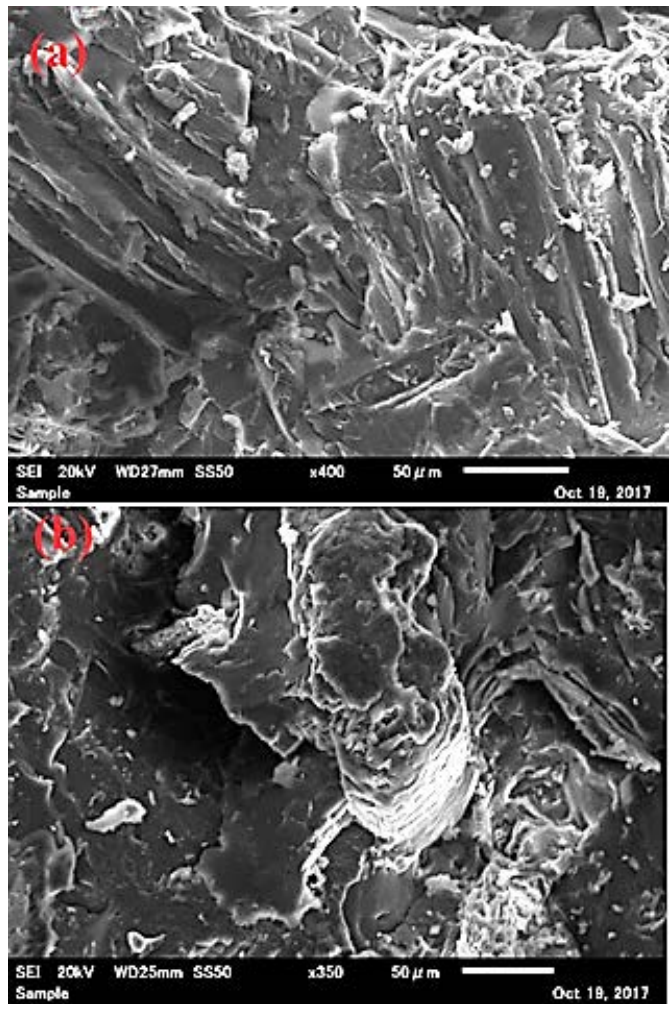

Figure 7. Fractured surface morphology and fiber/matrix adhesion in (a) PR/SD and (b) PR/RH WPCs after 7 days of UV exposure.

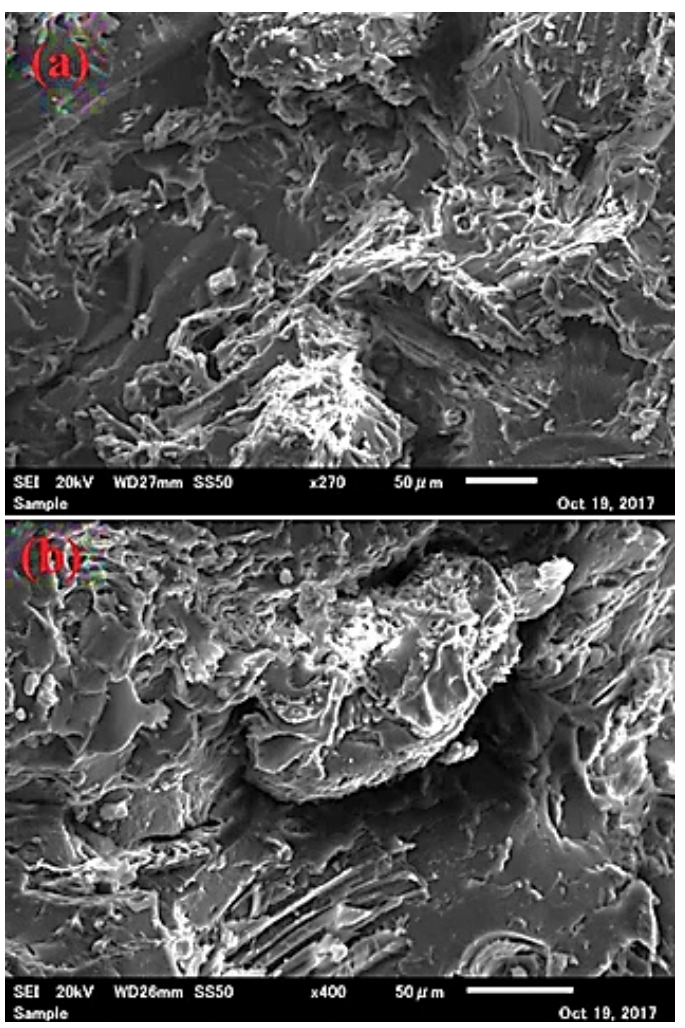

Figure 8. Fractured surface morphology and fiber/matrix adhesion in (a) PR/SD and (b) PR/RH WPCs after 12 days of UV exposure. 


\section{Conclusion}

We evaluated the thermal, mechanical and water absorption properties of wood-polymer composites made with phenolic resin filled with rice husks and sawdust. PR/SD showed better mechanical properties, but lower thermal stability and water resistance compared to PR/RH PWCs. However, considering the main applications of these types of composites, both composites showed relatively good properties. Nevertheless, the weathering effects considerably affects and lowers the mechanical and water resistance properties of both composites. Thus, we should consider using sodium hydroxide/silane treatment, plasma or ozone treatment on the fillers to increase the filler/matrix interfacial bond strength; as well as UV stabilizers, to limit photo-degradation effects, and Nanoclay to increase fire resistance. These treatments and additives could considerably optimize the composites performances and get the most of the desirable properties of $\mathrm{SD}$ and RH. In fact, rice husk and sawdust are among the most abundant biomass products produced worldwide every year. Therefore, using them as fillers for phenolic resin based wood-polymer composites could provide good added value to construction sector, especially in developing countries. Furthermore, regarding alarming Global warming effects, Green technologies are nowadays more than welcome in order to build a sustainable world for the future generation.

\section{Conflicts of Interest}

The authors declare no conflicts of interest regarding the publication of this paper.

\section{References}

[1] Väisänen, T., Haapala, A., Lappalainen, R. and Tomppo, L. (2016) Utilization of Agricultural and Forest Industry Waste and Residues in Natural Fiber-Polymer Composites: A Review. Waste Management, 54, 62-73. https://doi.org/10.1016/j.wasman.2016.04.037

[2] Kim, J.K. and Pal, K. (2010) Recent Advances in the Processing of Wood Plastic Composites. Springer-Verlag, Berlin Heidelberg, 2-7.

[3] Anastas, P.T. and Kirchhoff, M.M. (2002) Origins, Current and Future Challenges of Green Chemistry. Accounts of Chemical Research, 35, 686-694. https://doi.org/10.1021/ar010065m

[4] Ashori, A. (2008) Wood-Plastic Composites as Promising Green-Composites for Automotive Industries. Bioresource Technology, 99, 4661-4667. https://doi.org/10.1016/j.biortech.2007.09.043

[5] Leite, J.L., Pires, A.T.N., et al. (2004) Characterization of a Phenolic Resin and Sugar Cane Pulp Composite. Brazilian Journal of Chemical Engineering, 21, 253-260. https://doi.org/10.1590/S0104-66322004000200015

[6] Economy, J. and Pashar, Z. (2011) Historical Perspectives of Phenolic Resins. In: Seth, C. and Rasmussen, E. and Strom, T. Eds., 100+ Years of Plastics: Leo Baekeland and Beyond, OUP USA, San Francisco, 83-91. https://doi.org/10.1021/bk-2011-1080.ch006 
[7] Wang, J., Jianga, H. and Jiang, N. (2009) Study on the Pyrolysis of Phenol-Formaldehyde (PF) Resin and Modified PF Resin. Thermochimica Acta, 496, 136-142. https://doi.org/10.1016/j.tca.2009.07.012

[8] Bhavna, M. (2016) Properties and Industrial Applications of Rice Husk. International Journal of Engineering Science and Computing, 6, No.10.

[9] Reza, A., et al. (2015) Rice Husk Filled Polymer Composites. International Journal of Polymer Science, 2015, 32.

[10] Imre, K. and Vasile, A. (2016) About the Wood Sawdust-One of the Most Important Renewable Energy Sources. International Journal of Engineering, XIV, ISSN: 1584-2673.

[11] Chen, Y., Stark, N.M., et al. (2016) Weathering Characteristics of Wood Plastic Composites Reinforced with Extracted or Delignified Wood Flour. Materials, 9, 610. https://doi.org/10.3390/ma9080610

[12] Aigbomian, P.E. and Fan, M. (2013) Development of Wood-Crete from Hardwood and Softwood Sawdust. The Open Construction and Building Technology Journal, 7, 108-117. https://doi.org/10.2174/1874836801307010108

[13] Yang, H., Yan, R., et al. (2007) Characteristics of Hemicellulose, Cellulose and Luignin Pyrolysis. Journal of Analytical and Applied Pyrolysis, 86, 1781-1788.

[14] Ahiduzzaman, Md. and Sadrul Islam, A.K.M. (2015) Thermo-Gravimetric and Kinetic Analysis of Different Varieties of Rice Husk. Procedia Engineering, 105, 646-651. https://doi.org/10.1016/j.proeng.2015.05.043

[15] Coutinhoa, F.M.B., Costa, T.H.S., et al. (2000) Sawdust Reinforced Polypropylene Composites: A Study of Fracture Behavior. Polymer Testing, 19, 625-633. https://doi.org/10.1016/S0142-9418(99)00034-3

[16] Ndiaye, D., Fanton, E., et al. (2008) Durability of Wood Polymer Composites: Part1, Influence of Wood on Photochemical Properties. Composites Science and Technology, 68, 2279-2284. https://doi.org/10.1016/j.compscitech.2008.06.014

[17] Azwa, Z.N., Yousif, B.F., et al. (2013) A Review on the Degradability of Polymeric Composites Based on Natural Fibres. Materials and Design, 47, 424-442. https://doi.org/10.1016/j.matdes.2012.11.025

[18] Kim, J.K. and Pal, K. (2010) Recent Advances in the Processing of Wood-Plastic Composites. Springer-Verlag, Berlin Heidelberg. 